\title{
Malignant pleural effusions with unknown primary sites: A 6 years cytological study
}

\author{
Akashdeep Singh ${ }^{1}$, Shikha Aggarwal ${ }^{2}$, Neena Sood ${ }^{3}$, Pavneet Kaur Selhi ${ }^{4}$, Aminder Singh $^{5, *}$ \\ ${ }^{\mathbf{1}}$ Associate Professor, ${ }^{2}$ Senior Resident, ${ }^{3}$ Professor and Head, ${ }^{4}$ Professor, ${ }^{\mathbf{5}}$ Assistant Professor, ${ }^{1}$ Dept. of Pulmonary Medicine, \\ 2,3,4,5 Dept. of Pathology, ${ }^{1-5}$ Dayanand Medical College and Hospital, Ludhiana, Punjab, India
}

*Corresponding Author:

Email: dr_aminder_singh@dmch.edu

Received: $17^{\text {th }}$ January, 2018

Accepted: $2^{\text {nd }}$ April, 2018

\begin{abstract}
Introduction: Malignant pleural effusion is an important complication found in patients of advanced cancers and lead on to exudative effusions. Not much data is available regarding malignant pleural effusions with unknown primary sites so we had conducted a retrospective study to highlights the primary sites in cases of malignant pleural effusions.

Materials and Methods: The present study was conducted at a tertiary care centre at Ludhiana, Punjab. Retrospective analysis of case records of 104 patients, diagnosed as malignant pleural effusions on cell cytology out of 2948 cases of pleural fluids during a 6 years period (2012 to 2017) was done and the results were analysed to assess the causes and various primary sites of malignant pleural effusion.

Results and Conclusion: A total of 104 pleural fluid samples were found to be positive for malignancy out of 2948 cases of pleural fluids during the study period time. Lung carcinoma was found to be the most common cause of malignant pleural effusion. On morphology, adenocarcinoma was the most common type of cytological diagnosis in all pleural effusions. Unknown primary malignancies presented as pleural effusions in many cases with no specific signs \& symptoms. Cytological study can reveal the morphological diagnosis \& clinch the primary site of origin in more than $50 \%$ of cases. Cytological analysis of pleural fluid should be the initial diagnostic approach to diagnose malignant pleural effusions and tapped effusions must always be sent for cytological study.
\end{abstract}

Keywords: Effusion, Lung, Malignancy, Primary site.

\section{Introduction}

Malignant pleural effusion is an important complication found in patients of advanced cancers and leading cause of exudative effusions. Though not so common still patients with malignant pleural effusions presents as non specific signs \& symptoms relating to pulmonary system without any previous known history of malignancy. Pleural effusion is the collection of excess amount of fluid in the pleural cavity which is abnormal both qualitatively and quantitatively. ${ }^{1}$ Cytological smear analysis is performed to rule out the presence or absence of benign or malignant cells in the pleural effusions. ${ }^{2}$ Detailed history, clinical examination, radiological, biochemical and cytological examination of the pleural fluid is required to ascertain the exact cause. Accurate evaluation of the etiology of pleural effusions in cases with unknown primary tumors is important as the prognosis and subsequent treatment of these patients may vary depending upon the diagnosis given. Malignant pleural effusions are a common cause of morbidity and mortality in patients with advanced cancers. The most common malignancies associated with malignant pleural effusion are found to be from lung, breast and lymphomas. This study was done to analyze the various primary sites associated with malignant pleural effusions.

\section{Aims and Objectives}

Aim was to assess the role of cytology in cases of malignant pleural effusions with unknown primary sites and to find out the various primary sites by correlating with clinical findings \& investigations including histopathology.

\section{Materials and Methods}

This study was conducted at department of Pathology, Ludhiana, Punjab. Retrospective analysis of case records of patients diagnosed as malignant pleural effusion on cell cytology during a 6 years period from 2012 to 2017 was done and the results were analysed to assess the causes and various primary sites of malignant pleural effusion. The pleural fluid samples were received in the department and smears made from the sediment part of centrifuged fluid and stained with Giemsa, hematoxylin \& eosin and Papanicolaou stains. Total 104 out of 2948 fluids were assessed retrospectively which were given positive for malignancy without known primary site. Patients clinical records were assessed including recorded history, clinical examination, histopathology, radiological investigations including chest $\mathrm{X}$ ray, Computed Scans wherever available and other biochemical investigations to ascertain the primary site. Percentage assessment was done for each category separately. 


\section{Results}

Total 104 pleural fluid samples out of 2948 were found to be positive for malignancy during the study period time. Majority of patients belonged to age group of 61-80 yrs followed closely by age group of 41-60 yrs. (Table 1). Least numbers were from both extremes of age.

Table 1: Age distribution of cases

\begin{tabular}{|l|c|c|}
\hline \multicolumn{1}{|c|}{ Age } & No of patients & $\begin{array}{c}\text { Percentage (\%) } \\
\text { of the total } \\
\text { patients }\end{array}$ \\
\hline $0-20 y r s$ & 3 & 2.88 \\
\hline $21-40$ yrs & 10 & 9.6 \\
\hline $41-60$ yrs & 43 & 41.3 \\
\hline $61-80$ yrs & 44 & 42.3 \\
\hline$>80$ yrs & 4 & 3.8 \\
\hline Total & 104 & 100 \\
\hline
\end{tabular}

The youngest patient was 8 years old while the eldest was 90 years old.

Out of total 104 patients, 55 were females while 49 were males. (Table 2) Female to male ratio was 1: 0.89.

Table 2: Sex distribution of cases

\begin{tabular}{|l|c|}
\hline Male & $49(47.11 \%)$ \\
\hline Female & $55(52.88 \%)$ \\
\hline Total & $104(100 \%)$ \\
\hline
\end{tabular}

Retrospective analysis of patient data analysed and primary site was found in 44 cases only. In 39 cases, the primary site was confirmed on histopathology. Three cases were of acute leukemia were confirmed on flow cytometry analysis. One of the patient was already a known case of acute lymphoblastic leukemia. Another patient was a known case of multiple myeloma. Primary site remained unknown in around 57\% of cases even after extensive search. (Table 3)

Table 3: Showing known and unknown primaries

\begin{tabular}{|l|c|}
\hline Primary site found & 44 cases $(42.3 \%)$ \\
\hline $\begin{array}{l}\text { Primary site remain } \\
\text { unknown }\end{array}$ & 60 cases $(57.69 \%)$ \\
\hline
\end{tabular}

Retrospective analysis showed that lung was the commonest site followed by breast and (Fig. 1) ovary. (Table 4)

Lung was also most common primary site in males as compared to females where breast \& ovary were almost equal.

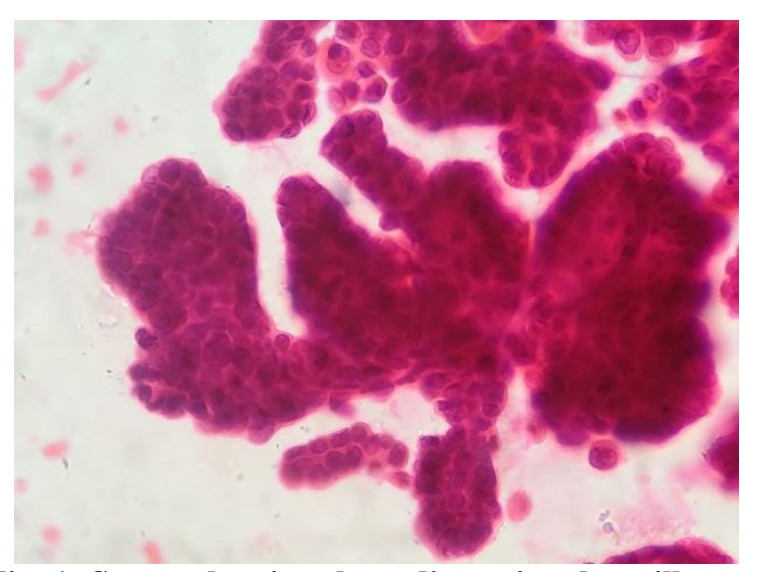

Fig. 1: Smear showing three dimensional papillary clusters in pleural fluid a case of carcinoma ovary (Hematoxylin \& eosin 40x)

Table 4: Known primary sites found in malignant pleural effusion both in males \& females

\begin{tabular}{|l|c|c|c|}
\hline \multicolumn{1}{|c|}{ Primary Site } & $\begin{array}{c}\text { Total number of patients with } \\
\text { primary site found }\end{array}$ & In Males & In Females \\
\hline Lung & $12(27.27 \%)$ & $10(22.72 \%)$ & $2(4.54 \%)$ \\
\hline Stomach & $2(4.54 \%)$ & $2(4.54 \%)$ & $0(0 \%)$ \\
\hline Breast & $10(22.72 \%)$ & $0(0 \%)$ & $10(22.72 \%)$ \\
\hline Ovary & $9(20.45 \%)$ & $0(0 \%)$ & $9(20.45 \%)$ \\
\hline Vertebra & $1(2.27 \%)$ & $1(2.27 \%)$ & $0(0 \%)$ \\
\hline Hematolymphoid Malignancy & $5(11.36 \%)$ & $2(4.54 \%)$ & $3(6.81 \%)$ \\
\hline Uterus & $2(4.54 \%)$ & $0(0 \%)$ & $2(4.54 \%)$ \\
\hline Liver & $1(2.27 \%)$ & $1(2.27 \%)$ & $0(0 \%)$ \\
\hline Tonsil & $1(2.27 \%)$ & $1(2.27 \%)$ & $0(0 \%)$ \\
\hline Colon & $1(2.27 \%)$ & $1(2.27 \%)$ & $0(0 \%)$ \\
\hline Total & $44(100 \%)$ & $18(40.90 \%)$ & $26(59.09 \%)$ \\
\hline
\end{tabular}

Lungs in males and breast in females were the leading primary sites. However, lung was the commonest primary site when data of both sexes combined. Morphologically adenocarcinoma was the most common followed by (Fig. 2) hematolymphoid neoplasms. (Table 5) Serous papillary adenocarcinoma from ovary and invasive ductal adenocarcinoma from breast were common. Leukemic infiltration of pleural fluid noted in 8 cases. Known hematolymphoid malignancy was observed in 5 cases. Of which, one case was of myelomatous pleural effusion while another case was of acute lymphoblastic leukemia. 


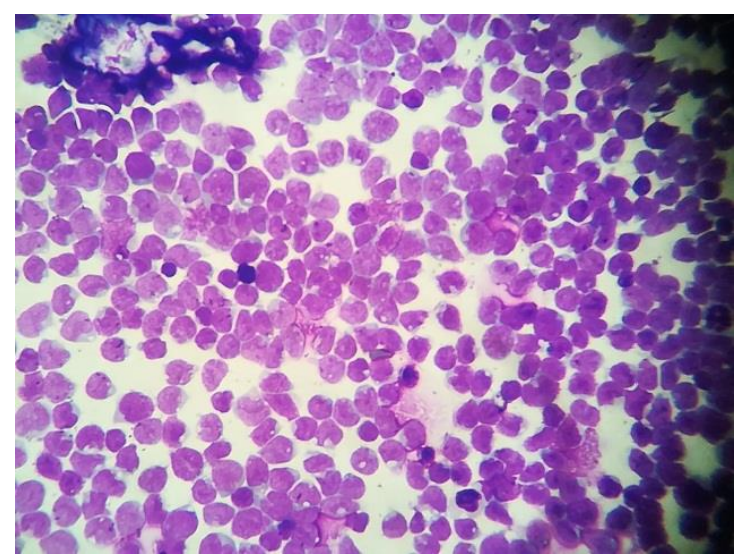

Fig. 2: Smear showing leukemic infiltration of pleural fluid (Giemsa 40x)

Table 5: Morphological diagnosis in all cases

\begin{tabular}{|l|c|c|c|c|}
\hline & Morphology & $\begin{array}{c}\text { Total } \\
\text { Cases }\end{array}$ & Male & Female \\
\hline Adenocarconima & & $95(91.34 \%)$ & $43(41.34 \%)$ & $52(50 \%)$ \\
\hline Haematolymphoid & -Multiple myeloma & $1(0.96 \%)$ & 0 & $1(0.96 \%)$ \\
& -Blastoid & $1(0.96 \%)$ & 0 & $1(0.96 \%)$ \\
& -Small to intermediate sized cell & $6(5.76 \%)$ & $5(4.81 \%)$ & $1(0.96 \%)$ \\
\hline Sarcoma & & $1(0.96 \%)$ & $1(0.96 \%)$ & 0 \\
\hline
\end{tabular}

Least common site was vertebra where malignant mesenchymal tumour was seen followed by (Fig. 3) stomach \& uterus.

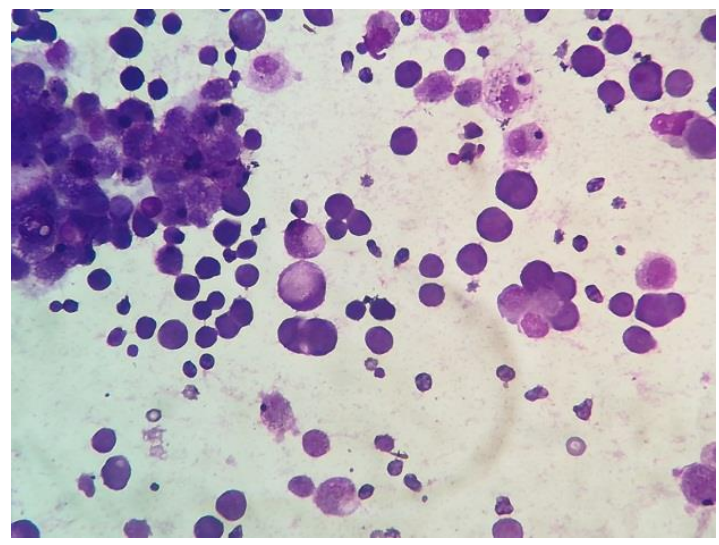

Fig. 3: Smear showing signet ring cells in a case of carcinoma stomach (Giemsa 40x)

Inspite of all efforts the primary site was remain unknown in around $57 \%$ of cases which was found to be a significant number.

\section{Discussion}

Cytopathological examination of the pleural fluid is easiest, simple \& cheapest method to diagnose malignant pleural effusion. Diagnostic yield is dependent on various factors like extent of the disease and site of the primary malignancy. In our study, malignant pleural effusions were the most common in the age group of 61-80 years. In this aspect our study has comparable results with other studies like Soe et al, ${ }^{3}$
Gadewad $\mathrm{N}$ et $\mathrm{al}^{4}{ }^{4}$ But, malignant pleural effusions were also reported in some patients at younger age group. The youngest casein our study had epithelioid sarcoma and was 8 years old. Our study showed female predominance while most of the other studies show male predominance. The finding of malignant cells in the pleural effusion indicates disseminated or advanced disease and associated with a reduced life expectancy in patients with malignant neoplasms.

Median survival after diagnosis ranges from 3 to 12 months which dependent on the stage of the primary malignant site and the type of underlying morphological malignant tumour. The shortest survival is observed in malignant pleural effusion due to lung cancer and longest survival in ovarian cancer while malignant pleural effusion due to unknown primary have intermediate survival time as reported by SanchezArmengol and Rodriguez-Pandero in 1993. ${ }^{5}$

In our study, the commonest known malignancy responsible for malignant pleural effusion in males was lung adenocarcinoma and in females, it was due to breast and ovary respectively. However, if we combine data of both sexes then lung cancer is the commonest malignancy responsible for malignant pleural effusion.

These findings are similar in literature, which shows that lung cancer is the most common metastatic tumour to the pleura in males and breast cancer in females. Reports from studies of springs and Boddington showed that these two accounted for $68 \%$ of malignant pleural effusions. ${ }^{6}$

Haematolymphoid malignancy cases accounted for the next highest frequency in our study. Postmortem studies suggest that most malignant pleural effusions 
result from tumour emboli to visceral pleura with secondary seeding to parietal pleura. ${ }^{7}$ Other possible mechanisms are direct tumour \& lymphovascular invasion. $^{8}$

Many patients presenting with malignant pleural effusion have moderate-to-large pleural effusions at the time of diagnosis, while only about $10 \%$ of patients have massive effusion at the time of diagnosis. ${ }^{7,8}$ Now a days, authors demonstrated that ultrasound helps in identifying pleural lesions in patients with malignant pleural effusion and is also helpful in directing thoracocentesis in cases of small effusions thus avoiding thoracocentesis complications. ${ }^{9}$

Almost all the malignant effusions diagnosed on cytology were adenocarcinomas and the yield was less with other malignancies like sarcomas, squamous cell carcinomas, Hodgkin's disease. ${ }^{10,11}$ This might be because of the fact that the adenocarcinoma cells are more easily identified cytological and large tissue biopsies are usually needed for the diagnosis of lymphoma and sarcomas.

Our study showed that in developing countries, where investigations and health facilities are not adequate and cost of treatment is many times unaffordable, pleural fluid analysis and cytology should be continued as a first line investigation to screen out the suspiciously malignant pleural effusion cases, because it is not only a very convenient, cost-effective but also a safe investigation. As all studies have some cons, the major drawback of our study was that it was a retrospective study, and data may be missing regarding the actual known primary cases.

\section{Conclusion}

Pleural fluid cytology is helpful in diagnosing malignant pleural effusion. The above study shows that it is encountered in almost all age groups, but more common in the middle aged and elderly. The most common known primary causing malignant pleural effusion is due to lung cancer in males and breast and ovarian malignancy in females. Together lung cancer is the leading cause of malignant pleural effusion among both the sexes. Tapped pleural fluid must be submitted for cytological assessment. Cytology is quite accurate tool for the primary assessment of all pleural effusions to ascertain the cause for proper management of patients.
Acknowledgement: None

\section{Conflicts of Interest: None}

\section{References}

1. Anthony Seaton, crofton and Douglas's Respiratory Disease 5th edition. 2000;43:1152-80.

2. Noppen, Mare M, Waele' MD, Lir, Gucht LKV, D’Laere $\mathrm{J}$, Gerlo E,. et al. Volume and cellular content of not kmal pleural fluid in humans examined by pleural lavage.

Amer. American Journal of Respiratory and critical care Medicine. 2000;162(3);1023-6.

3. Soe Z, Aung Z, Tun KD. A Clinical Study on Malignant Pleural Effusion. International Journal of Collaborative Research on Internal Medicine \& Public Health. 2012;4:761-779.

4. Gadewad N, Deokar K, Ghorpade S. Clinical Profile of Patients Presenting with Malignant Pleural Effusion to a Tertiary Health Care Centre. Journal of the Association of Physicians of India. 2017;65:28-31.

5. Sanchez-Armengol A, Rodriguez-Panadero F. Survivaland talc pleurodesis in metastatic pleural carcinoma: revisited. Report on 125 cases. Chest. 1993;104(5):1482-1485.

6. Light RW. Pleural diseases. 4th ed. Philadelphia, PAUSA: Lippincott Williams \& Wilkins 2001.

7. Sahn SA. Pleural diseases related to metastatic malignancies. Eur Respir J. 1997;10(8):1907-1913.

8. American thoracic society. Management of malignant pleural effusions. Am J Respir Crit Care Med. 2000;162(5):1987-2001.

9. Grogan DR, Irwin RS, Channick R, et al. Complications associated with thoracentesis: a prospective, randomized study comparing three different methods. Arch Intern Med. 1990;150(4):873-877.

10. Tetikkurt C, Y1lmaz Kara B, Tetikkurt S, Y1lmaz N, Ilknur Yasar Rian Disci. The Value of Cytology in the Diagnosis of Pleural Effusions. British Journal of Medicine \& Medical Research. 2014;4(11): 2203-11.

11. Viswanathan VK. Study of the causes and diagnostic modalities of malignant pleural effusions in the prethoracoscopy era in a tertiary care centre. J. Evid. Based Med. Healthc. 2017;4(44), 2682-2684.

How to cite this article: Singh A, Aggarwal S, Sood N, Selhi PK, Singh A. Malignant pleural effusions with unknown primary sites: A 6 years cytological study. Ind J Pathol Oncol, 2018;5(3):450-453. 